\title{
Continuous administration of recombinant human endostatin (Endostar): A pre-clinical safety study
}

\author{
RUOFAN HUANG ${ }^{1,2^{*}}$, QIONG ZHAN ${ }^{1,2^{*}}$, XINLI ZHOU ${ }^{1,2}$, ZHAOHUI CHU $^{1,2}$, \\ JINGWEI JIANG ${ }^{1,2}$ and XIAOHUA LIANG ${ }^{1,2}$ \\ ${ }^{1}$ Department of Oncology, Huashan Hospital, Fudan University, Shanghai 200040; \\ ${ }^{2}$ Department of Oncology, Shanghai Medical College, Fudan University, Shanghai 200032, P.R. China
}

Received February 1, 2012; Accepted March 20, 2012

DOI: $10.3892 / \mathrm{etm} .2012 .534$

\begin{abstract}
The aim of this study was to evaluate the safety of the continuous administration of recombinant human endostatin (Endostar) in healthy mice. A total of 16 nude mice were randomly divided into four treatment groups: a continuous administration group injected intraperitoneally (i.p.) with $14 \mathrm{mg} / \mathrm{kg}$ Endostar over seven days, an intermittent administration group injected i.p. with $2 \mathrm{mg} / \mathrm{kg}$ Endostar daily for seven days, a saline injection group and an untreated control group. All mice were implanted with an intraperitoneal mini-osmotic drug pump filled with Endostar or saline. The serum concentration of Endostar, the cell fraction of CD11b ${ }^{-}$D $146^{+} \mathrm{CD} 105^{+}$ vascular endothelial cells in the peripheral blood, the injury of the myocardial, lung and kidney tissues and the density of microvessels within these organs were observed $24 \mathrm{~h}$ after the termination of drug or saline administration. Only trace amounts of Endostar were detected in the serum of the continuous administration and intermittent administration groups. Myocardial, lung and kidney tissues exhibited no detectable signs of injury and no differences in the density of microvessels were found in these organs among the four groups. Yet, the cell fraction (in \%) of $\mathrm{CD} 11 \mathrm{~b}-\mathrm{CD} 146^{+} \mathrm{CD} 105^{+}$vascular endothelial cells in the peripheral blood was higher in the continuous administration group compared with that in the other treatment groups $(\mathrm{P}=0.011)$. This suggests that intermittent Endostar delivery did not significantly impact the vascular endothelium, while continuous Endostar administration may promote injury of the endothelium. In conclusion, the continuous administration of Endostar does not appear to be a safe method by which to administer this antiangiogenic agent to healthy nude mice.
\end{abstract}

Correspondence to: Dr Xiaohua Liang, Department of Oncology, Huashan Hospital, Fudan University, No. 12 Middle Urumqi Road, Shanghai 200040, P.R. China

E-mail: xiaohualiang2009@gmail.com

${ }^{*}$ Contributed equally

Key words: endostatin, vascular endothelial cells, microvessel count, safety

\section{Introduction}

Recombinant human endostatin (Endostar, Simcere Pharmaceutical Group, China) is a modified human endostatin with a nine amino acid sequence at the $\mathrm{N}$-terminus (MGGSHHHHH) that significantly exhibits increased heat stability and proteolytic resistance compared with the endogenous protein (1). Endostar, in combination with vinorelbine plus cisplatin (the NP regimen), significantly lengthens the progression-free survival of patients with non-small cell lung cancer (NSCLC) and Endostar plus paclitaxel-carboplatin improves the overall survival of NSCLC patients (2). It is recommended that Endostar is administered once per day over four hours. The half-life of Endostar in vivo is only $10 \mathrm{~h}$, so continuous administration may augment the anticancer effects. However, it is unclear whether continuous administration results in additional adverse side effects. To evaluate the safety of the continuous administration of Endostar, we conducted a pre-clinical study in nude mice, using a ubiquitous immunocompromised cancer model.

\section{Materials and methods}

Animals. A total of 16 female nude mice (weighing approximately $20 \mathrm{~g}$ ) were used in this study. The dosage was converted from clinical dosage, taking into consideration the body surface area of the nude mice and the bioavailability of the intraperitoneal (i.p.) method, and daily dosage was calculated as $2 \mathrm{mg} / \mathrm{kg}$. A total of 12 mice were anesthetized by i.p. injection with $10 \%$ chloral hydrate and implanted with an intraperitoneal miniosmotic drug pump (ALZET 107D, Durect Corp., Cupertino, CA, USA) which released drug continuously for seven days. The mice were randomly divided into three groups of four mice each. The drug pumps in the continuous administration group were filled with $14 \mathrm{mg} / \mathrm{kg}$ Endostar (diluted in $100 \mu \mathrm{l}$ saline) and the mice were injected i.p. with $100 \mu 1$ saline daily. The drug pumps in the intermittent administration group were filled with $100 \mu \mathrm{l}$ saline and the mice were injected i.p. with $2 \mathrm{mg} / \mathrm{kg}$ Endostar (diluted in $100 \mu \mathrm{l}$ saline) daily for seven days. The drug pumps in the saline group were filled with $100 \mu \mathrm{l}$ saline and the mice were injected i.p. with $100 \mu \mathrm{l}$ saline for seven days. The remaining four mice constituted the control group. The weight, activity and eating behaviors of the mice 
Table I. Body weights $(\mathrm{g})$ of the mice in the different treatment groups.

\begin{tabular}{lcccc}
\hline & $\begin{array}{c}\text { Control group } \\
(\mathrm{n}=4)\end{array}$ & $\begin{array}{c}\text { Saline group } \\
(\mathrm{n}=3)\end{array}$ & $\begin{array}{c}\text { Intermittent administration } \\
\text { group }(\mathrm{n}=3)\end{array}$ & $\begin{array}{c}\text { Continuous administration } \\
\text { group }(\mathrm{n}=3)\end{array}$ \\
\hline Prior to Endostar & $19.4 \pm 1.2$ & $18.6 \pm 0.7$ & $18.9 \pm 2.7$ & $20.6 \pm 0.4$ \\
Following Endostar & $21.4 \pm 1.1$ & $18.9 \pm 1.3$ & $18.4 \pm 3.8$ & $21.2 \pm 0.2$ \\
P-value & 0.047 & 0.739 & 0.852 & 0.052 \\
\hline
\end{tabular}

were measured daily. All mice were sacrificed on the eighth day and whole blood and serum were collected. In addition, hearts, kidneys and lungs were removed and examined histochemically for Endostar-induced damage. The experimental protocol was approved by the Shanghai Medical Experimental Animal Care Committee.

Determination of Endostar serum concentrations. The assay was performed as described by Paborsky et al (3). Endostar was diluted to $400 \mathrm{ng} / \mathrm{ml}$ in serum from the drug-free mice and then serially diluted to $6.25 \mathrm{ng} / \mathrm{ml}$ with a sample dilution buffer to establish the standard curve. These Endostar and mouse serum samples were diluted with $100 \mathrm{mM} \mathrm{NaAc}$ (pH 5.5), followed by incubation on Ni-coated plates (Qiagen, Hamburg, Germany) overnight at $4^{\circ} \mathrm{C}$. The serum-Endostar solution was incubated with biotinylated goat anti-human endostatin antibody (R\&D Systems, Minneapolis, MN, USA) for $2 \mathrm{~h}$ at room temperature and then with streptavidin-HRP (Pierce Biotechnology, Inc., Rockford, IL, USA) for $1 \mathrm{~h}$ at room temperature. Finally, the labeled solution was incubated with the chromogen 3,3',5,5'-tetramethylbenzidine (TMB) for $20 \mathrm{~min}$ at room temperature. The Endostar concentration was determined by measuring the absorbance at $450 \mathrm{~nm}$ and calculated by four parameter logistics according to the standard curve. The assay had been validated by the Simcere Pharmaceutical Group using standard Endostar with a detection limit of 12.5-400 ng/ml. The mean recovery was $101.7 \%$, the mean coefficient of correlation was 1 and the mean RE of every data point was $0.304 \%$ (unpublished data from Simcere Pharmaceutical Group).

Flow cytometric analysis. Red blood cells from mouse peripheral blood $(100 \mu \mathrm{l})$ were lysed and washed. Antibodies against CD11b, CD146 and CD105 were used. The antibodies were conjugated to fluorescein isothiocyanate (FITC), phycoerythrin (PE) or allophycocyanin (APC). Appropriate isotype-matched controls were used in all experiments. All the antibodies and reagents were purchased from Biolegend (San Diego, CA, USA). The cells were incubated with the antibodies for $25 \mathrm{~min}$ at $4^{\circ} \mathrm{C}$. Following incubation, the cells were washed twice and analyzed using a FACScan cytometer with CellQuest software (BD Biosciences, San Jose, CA, USA).

Histology and immunohistochemical staining. Formalinfixed, paraffin-embedded heart, lung and kidney tissues were routinely stained with hematoxylin and eosin (H\&E). For CD146 staining, the tissue sections were fixed in $10 \%$ formalin and treated with anti-CD146 (1:100; Biolegend), followed by staining of rabbit anti-mouse IgG and development with 3,3-diaminobenzidine (DAB). The sections were counterstained with hematoxylin and examined under light microscopy (x200).

Microvessel counts. Microvessel counts of the tissues were performed as previously described (4). Briefly, any brown stained endothelial cell or cluster was considered to be a single, countable microvessel. The areas of highest neovascularization were identified by scanning the tissue sections at low magnification (x40). After the area of highest neovascularization was identified, individual microvessel counts were performed on five fields per specimen (x200). We obtained a mean value per specimen from these five fields to calculate the microvessel count for each tissue.

Statistical analysis. Statistical analyses were performed using the SPSS 15.0 statistical software package (SPSS, Inc., Chicago, IL, USA). All data are reported as the mean \pm SD. The differences were analyzed by one-way analysis of variance (ANOVA) or t-test. $\mathrm{P}<0.05$ was considered to indicate a statistically significant difference.

\section{Results}

Weight changes in the treatment groups. The body weight of the mice in the control group increased after seven days, while the mice in the three injection groups exhibited no significant changes in body weight over seven days of Endostar or saline administration. One mouse in each of the injection groups with i.p. mini-osmotic drug pumps died during the course of treatment (Table I). No significant difference in the motor activity or eating behaviors among the injection groups was observed.

Endostar concentration in serum. The concentration of Endostar in serum samples from each mouse in the intermittent and continuous administration groups was measured $24 \mathrm{~h}$ after the termination of drug administration. In both groups, only residual traces of Endostar were detected and the average serum concentration was not significantly different between the groups $(20.6 \pm 13.9$ vs. $26.3 \pm 5.5 \mathrm{ng} / \mathrm{ml}, \mathrm{P}=0.547)$

Fraction of $\mathrm{CD} 11 \mathrm{~b}^{-} \mathrm{CD} 146^{+} \mathrm{CD} 105^{+}$cells in the peripheral blood nucleated cell population. The fraction of CD11b CD $146^{+} \mathrm{CD} 105^{+}$cells in the peripheral blood nucleated cell population in the continuous administration group $(4.41 \pm 1.46 \%)$ was higher than that in the intermittent $(1.05 \pm 0.15 \%)$, saline $(1.16 \pm 0.55 \%)$ and control groups $(1.49 \pm 1.30 \% ; P=0.011 ;$ Fig. 1$)$.

Histology. Tissue histology of the hearts, kidneys and lungs revealed no clear signs of injury in any of the treatment groups 
A

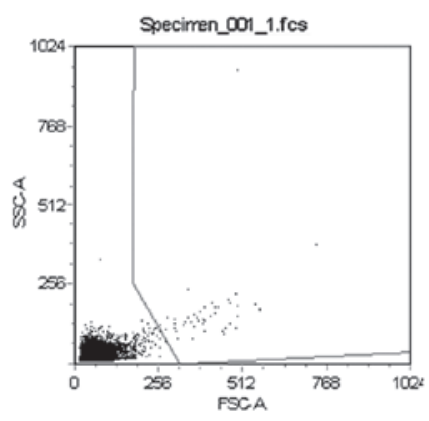

B

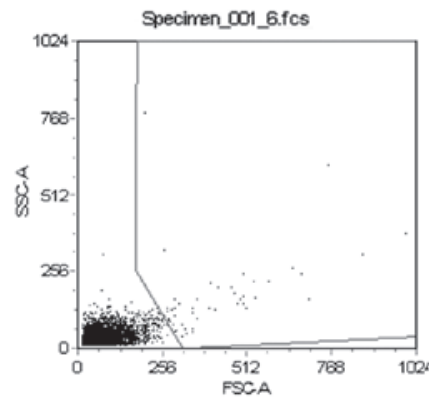

C

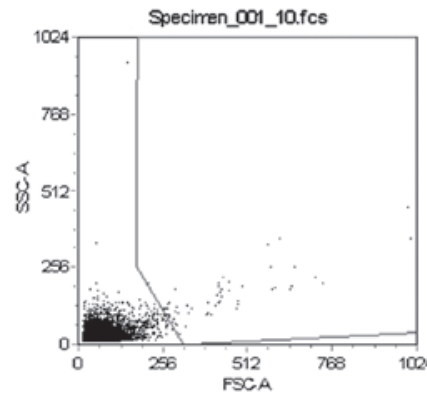

D

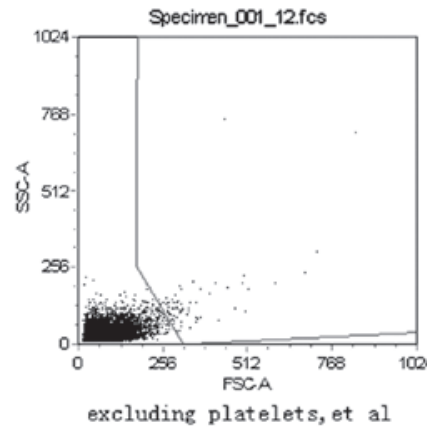

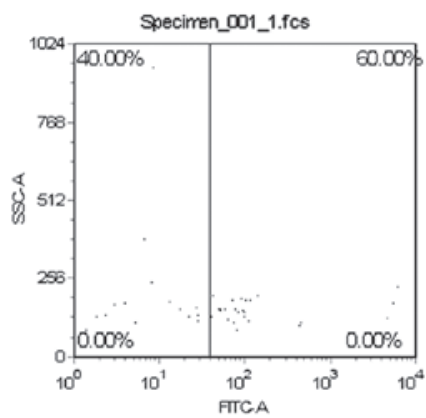
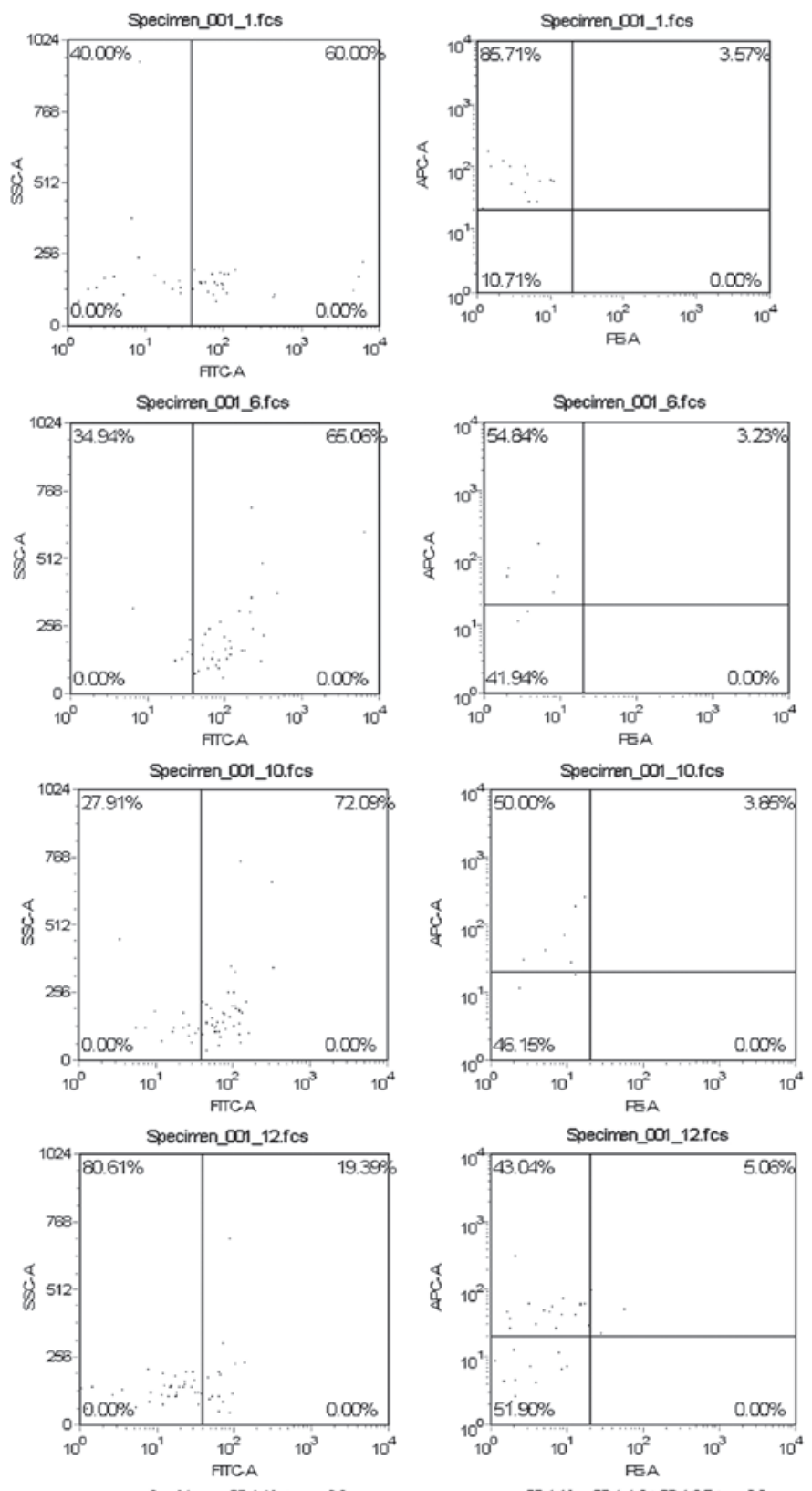

CD11b-CD146+CD105+cells

Figure 1. Flow cytometric analysis of $\mathrm{CD} 11 \mathrm{~b}-\mathrm{CD} 146^{+} \mathrm{CD} 105^{+}$cells in the peripheral blood nucleated cell population in (A) the control group, (B) saline group, (C) intermittent administration group and (D) continuous administration group. FITC:CD11b, PE:CD146, APC:CD105. FITC, fluorescein isothiocyanate;

PE, phycoerythrin; APC, allophycocyanin.

Table II. CD146-labeled microvessels in heart, kidney and lung tissue.

\begin{tabular}{lccccr}
\hline Organ & $\begin{array}{c}\text { Control group } \\
(\mathrm{n}=4)\end{array}$ & $\begin{array}{c}\text { Saline group } \\
(\mathrm{n}=3)\end{array}$ & $\begin{array}{c}\text { Intermittent administration } \\
\text { group }(\mathrm{n}=3)\end{array}$ & $\begin{array}{c}\text { Continuous administration } \\
\text { group }(\mathrm{n}=3)\end{array}$ & P-value \\
\hline Myocardium & $132.3 \pm 8.1$ & $131.3 \pm 10.0$ & $125.3 \pm 13.1$ & $127.7 \pm 8.7$ & 0.820 \\
Kidney & $74.0 \pm 6.9$ & $72.3 \pm 4.0$ & $69.3 \pm 12.5$ & $77.3 \pm 4.2$ & 0.638 \\
Lung & $6.3 \pm 2.1$ & $6.0 \pm 2.0$ & $5.3 \pm 1.5$ & $6.7 \pm 0.6$ & 0.806 \\
\hline
\end{tabular}

(Fig. 2). Edema, necrosis and hemorrhage were not noted in the tissues of heart, kidney and lung in the intermittent and continuous administration groups, similar to tissues in the saline group.
Microvessel counts. The number of CD146-labeled microvessels in heart, kidney and lung tissues were not found to be significantly different among the four groups (Table II, Fig. 3). 


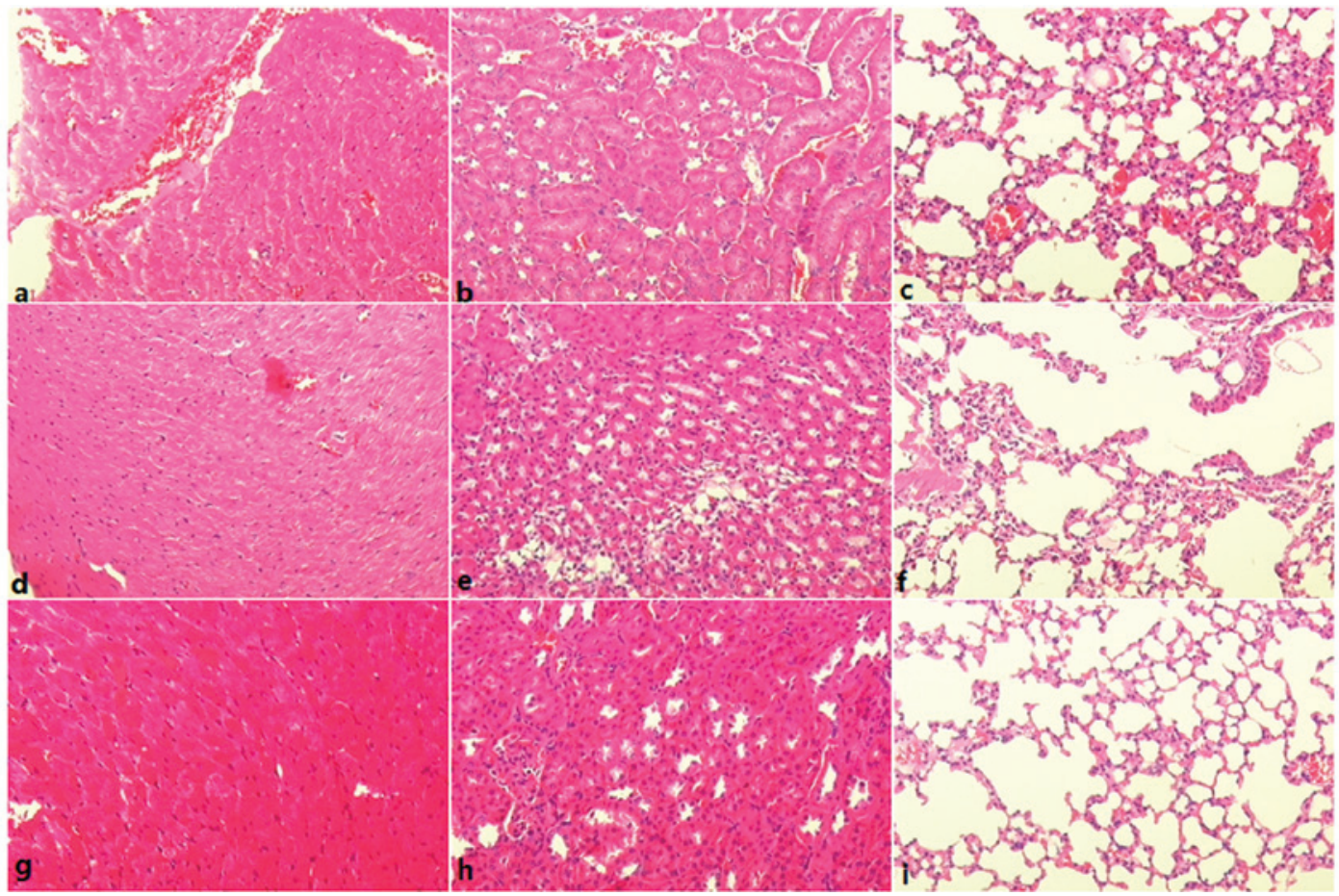

Figure 2. Histologic findings in heart, kidney and lung tissues following Endostar administration (H\&E staining, x200). (A-C) Tissues of (A) heart, (B) kidney and (C) lung in the saline group. (D-F) Tissues of (D) heart, (E) kidney and (F) lung in the intermittent administration group. (G-I) Tissues of (G) heart, (H) kidney and (I) lung in the continuous administration group. H\&E, hematoxylin and eosin.

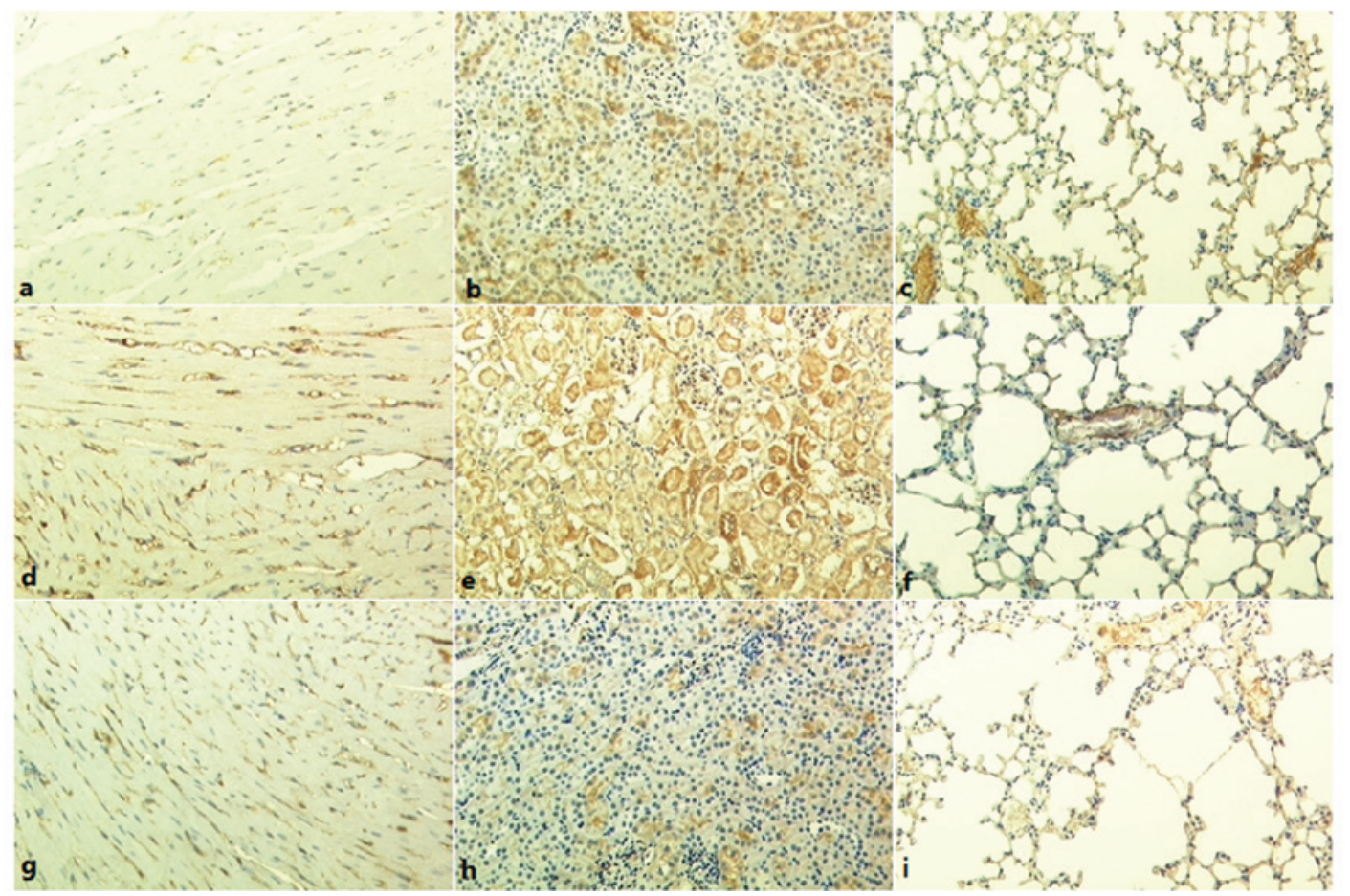

Figure 3. CD146-labeled microvessels in heart, kidney and lung tissues following Endostar administration (x200). (A-C) CD146-labeled microvessels in the tissues of (A) heart, (B) kidney and (C) lung in the saline group. (D-F) CD146-labeled microvessels in the tissues of (D) heart, (E) kidney and (F) lung in the intermittent administration group. (G-I) CD146-labeled microvessels in the tissues of (G) heart, (H) kidney and (I) lung in the continuous administration group.

\section{Discussion}

Antiangiogenesis therapy has great potential for cancer treatment, but the clinical efficacy of drugs such as the humanized vascular endothelial growth factor (VEGF) monoclonal anti- body bevacizumab and Endostar has not been satisfactory. Previous efforts have focused on enhancing the treatment efficacy by modifying the timing, sequence or dose of the antiangiogenic drugs in combination with cytotoxic chemotherapy drugs $(5,6)$. In our previous study concerning the correlation 
between the dose and efficacy of Endostar, we found an effective dose range beyond which the effect on tumor growth decreased (data not shown). In the present study, we hypothesized that the continuous administration of Endostar may augment the antitumor effects. It is not known, however, whether the continuous administration of Endostar disrupts angiogenesis in cancer tissues while sparing normal tissues. To this end, we observed the impact of the continuous administration of Endostar on normal heart, kidney and lung tissues in nude mice.

The mini-osmotic pump was used to control the timing of i.p. injection. It has been demonstrated that the zinc ion structure of Endostar allows the molecule to withstand higher temperatures and proteolysis by trypsin, chymotrypsin and carboxypeptidase, so prolonged drug administration times should not impact drug activity (1). In order to preclude the effects of residual drug released from the osmotic pump $24 \mathrm{~h}$ after termination of pump flow, we compared the concentration of Endostar in serum in the intermittent administration group with that in the continuous administration group at that time point. Only nanogram amounts of drug were detected in the serum of the two groups and there was no difference, indicating that the difference between the two groups was not due to the residual Endostar in the pump.

No significant difference was observed in the motor activity, weight or eating behaviors between mice in the intermittent administration, continuous administration and saline groups, although the weight of the control mice did increase, which may be the result of implantation surgery. This suggests that intermittent drug administration, continuous drug administration and saline administration did not have a significant impact on the general health or feeding habits of the surviving test mice. The mortality of the mice was $1 / 4$ in the intermittent administration, continuous administration and the saline groups and all the mice were implanted with mini-pumps. Moreover, these deaths all occurred within $24 \mathrm{~h}$ of pump implantation, suggesting that mortality arose from i.p. implantation surgery rather than from drug injection.

We determined the relative number of vascular endothelial cells with the expression pattern $\mathrm{CD} 11 \mathrm{~b}-\mathrm{CD} 146^{+} \mathrm{CD} 105^{+}$in the peripheral blood. The phenotyping of vascular endothelial cells by surface antigens remains controversial, especially for mice, so we selected CD146 as one of the antigens as it is a vascular endothelial cell marker common to humans and mice. The surface expression of CD146 is found in human T and B lymphocytes, while it is expressed in the $\mathrm{CD}_{11 \mathrm{~b}^{+}}$natural killer (NK) cells and neutrophils of mice (7). Thus, the CD11b CD146 ${ }^{+}$expression pattern should exclude NK cells and neutrophils in mice. Vascular endothelial cells which are involved in angiogenesis are $\mathrm{CD}_{105^{+}}(8,9)$. The number of $\mathrm{CD} 105^{+}$vascular endothelial cells in peripheral blood may reflect vascular injury and renewal. In normal tissues, only $0-1 \%$ of vascular endothelial cells renew daily. Moreover, the number of vascular endothelial cells in peripheral blood is small in samples from healthy mice, while this number increases significantly following vascular injury (10-13). The present study found a significant increase in $\mathrm{CD} 11 b^{-} \mathrm{CD} 146^{+} \mathrm{CD} 105^{+}$cells in the continuous administration group, while no significant difference was found among the control, saline and intermittent administration groups after seven days. This suggested that intermittent Endostar delivery did not significantly impact the vascular endothelium, while continuous Endostar administration may promote injury of the endothelium.

A randomized, double-blind, placebo-controlled study found that Endostar plus chemotherapy caused only grade 1 and grade 2 cardiac ischemia in patients, but no significant difference was noted in overall survival and progressive-free survival between the treatment and contol groups (2). Although in the present study the histological structure of myocardial, kidney and lung tissues was not detectably affected and immunohistochemical staining analysis did not reveal any significant differences in microvessel density in these organs between the groups, we suggest that continuous Endostar administration injures vascular endothelium, as evidenced by the increased number of $\mathrm{CD} 11 \mathrm{~b}-\mathrm{CD} 146^{+} \mathrm{CD} 105^{+}$cells in the peripheral blood compared with the other groups. The safety of continuous Endostar administration to healthy nude mice is therefore a valid concern.

In conclusion, the continuous administration of Endostar increases the number of $\mathrm{CD} 11 \mathrm{~b}^{-} \mathrm{CD} 146^{+} \mathrm{CD} 105^{+}$vascular endothelial cells in the peripheral blood, suggesting injury to normal vessels, although no histological injury of myocardium, kidney or lung was found following seven days of treatment. Therefore, we suggest that the continuous administration of Endostar may not be safe for healthy mice.

\section{References}

1. Jiang LP, Zou C, Yuan X, Luo W, Wen Y and Chen Y: N-terminal modification increases the stability of the recombinant human endostatin in vitro. Biotechnol Appl Biochem 54: 113-120, 2009.

2. Han B, Xiu Q, Wang H, Shen J, Gu A and Luo Y: A multicenter, randomized, double-blind, placebo-controlled study to evaluate the efficacy of paclitaxel-carboplatin alone or with endostar for advanced non-small cell lung cancer. J Thorac Oncol 6: 1104-1109, 2011.

3. Paborsky LR, Dunn KE, Gibbs CS and Dougherty JP: A nickel chelate microtiter plate assay for six histidine-containing proteins. Anal Biochem 234: 60-65, 1996.

4. Weidner N, Carroll PR, Flax J, Blumenfeld W and Folkman J: Tumor angiogenesis correlation with metastasis in invasive prostate carcinoma. Am J Pathol 143: 401-409, 1993.

5. Shaked Y, Henke E, Roodhart JM, et al: Rapid chemotherapyinduced acute endothelial progenitor cell mobilization: implications for antiangiogenic drugs as chemosensitizing agents. Cancer Cell 14: 263-273, 2008.

6. Celik I, Surucu O, Dietz C, et al: Therapeutic efficacy of endostatin exhibits a biphasic dose-response curve. Cancer Res 65: 11044-11050, 2005.

7. Despoix N, Walzer T, Jouve N, et al: Mouse CD146/MCAM is a marker of natural killer cell maturation. Eur J Immunol 38: 2855-2864, 2008.

8. Dallas NA, Samuel S, Xia L, et al: Endoglin (CD105): A marker of tumor vasculature and potential target for therapy. Clin Cancer Res 14: 1931, 2008.

9. Khan SS, Solomon MA and McCoy JP Jr: Detection of circulating endothelial cells and endothelial progenitor cells by flow cytometry. Cytometry B Clin Cytom 64: 1-8, 2005.

10. Abdelmoneim SS, Talwalkar J, Sethi S, Kamath P, et al: A prospective pilot study of circulating endothelial cells as a potential new biomarker in portal hypertension. Liver Int 30: 191-197, 2010.

11. Goon PK, Boos CJ and Lip GY: Circulating endothelial cells: markers of vascular dysfunction. Clin Lab 51: 531-538, 2005.

12. Dome B, Timar J,Ladanyi A, Paku S, Renyi-Vamos F, Klepetko W, et al: Circulating endothelial cells, bone marrow-derived endothelial progenitor cells and proangiogenic hematopoietic cells in cancer: from biology to therapy. Crit Rev Oncol Hematol 69: 108-124, 2009.

13. Erdbruegger U, Haubitz M and Woywodt A: Circulating endothelial cells: A novel marker of endothelial damage. Clin Chim Acta 373: 17-26, 2006. 